\title{
Exploring water scarcity in dryland India
}

ZAREen PERVEZ BHARUCHA

zpbhar@essex.ac.uk

Essex Sustainability Institute, University of Essex

This paper interrogates the 'naturalization' of water scarcity and outlines its implications for the sustainable management of land and water in India.

Some 622 million Indian farmers live and work in 'water limited' landscapes which fall outside the command of irrigation infrastructures such as dams and canals. These farmers face particularly urgent social-ecological challenges, including land degradation, poverty and hunger. These overlap in the drylands and have become chronic challenges. The primary response to these has been a nationwide programme of watershed development, which is designed to engage farming communities in participatory soil and water conservation, reforestation and livelihood diversification. These projects have now become the mainstay of rural de- 
velopment and are widely lauded as an example of participatory action and integrated development that links resource conservation with development objectives. Unfortunately, the programme as a whole has met with limited success. Reports of agrarian distress continue to emanate from rainfed farms.

Existing scholarship has largely attributed this to ineffective rural development practice. A core argument has been that outcomes are suboptimal because people's participation is either inadequate or impossible. A related stream of critique highlights inequitable distribution of costs and benefits across different social groups. More fundamental critiques have also emerged, exploring the basic premises of watershed development. These particularly interrogate its claims of forming a radical alternative to conventional land and water management (e.g. Daftary, 2013; Bharucha et al. 2014). The aim of this paper is to complement and extends these analyses through a critical exploration of the overarching metanarratives guiding land, water and rural development in India.

To do this I first analyse how dryland agri- 
culture is framed by key state and civil society stakeholders. This analysis particularly focusses on how water scarcity is assumed to be the key limiting factor to productive dryland livelihoods, and on how scarcity is overtly 'naturalized' i.e., attributed primarily to climatic features. I then discuss the reasons why these framings present an incomplete diagnosis leading to perverse outcomes for dryland farmers. I conclude the paper with reflections on more suitable ways forward, including greater investment in water-saving agronomies.

\section{Keywords}

Sustainable management, water scarcity, rural development, water-saving agronomies.

\section{References List}

Daftary, D. (2013) “Watershed development and neoliberalism in India's drylands", Journal of International Development, 26(7): 999-1010.

Bharucha, Z.P., Smith, D. and Pretty, J. (2014) All

Paths Lead to Rain: Explaining why Watershed 
Development in India Does Not Alleviate the Experience of Water Scarcity, The Journal of Development Studies, 50(9): 1209-1225.

PIJ/Volume 1 - Issue 2/2016 - 50 -

ISSN: 2499-1333 